Derecho \& Realidad

Núm. 21 • I semestre de 2013

Facultad de Derecho y Ciencias Sociales, UPTC

ISSN: 1692-3936

\title{
Jus connubii y matrimonio igualitario en el sistema internacional de derechos humanos
}

\author{
Jusconnubii and equal (gay) marriage in the \\ international human rights system
}

\author{
Víctor Luis Gutiérrez Castillo*
}

\section{Resumen}

La discriminación por orientación sexual, el matrimonio, la homoparentalidad, fueron algunas de las cuestiones debatidas en estetrabajo. Aquí se hizo un estudio sobre el matrimonio igualitario y su fundamento en los textos internacionales de derechos humanos, se planteó un análisis jurídico del ius connubii, su interpretación y aplicación en la práctica. Dicho análisis servirá también para valorar las diferentes fórmulas que, junto con la institución del matrimonio, se presentan en algunos países como "soluciones alternativas" a las demandas de derechos del colectivo LGTB; fórmulas que responden a características bien distintas según la realidad histórica, sociológica y política de cada país ${ }^{1}$. Todas estas instituciones son consideradas por movimientos de derechos humanos como fórmulas apartheid, en cuanto fomentan la discriminación y crean una ciudadanía limitada o de segunda categoría (Pezzini, 2010, p. 1-25).

Phd. Profesor Universidad de Jaén. Investigador Universidad La Sorbona de París.

En este sentido, en el derecho comparado encontraremos desde las legislaciones que solamente admiten algún tipo de unión civil de grado inferior al matrimonio -ya sea bajo la forma de registro de parejas, (registered partnerships), cohabitación registrada o cohabitación no registrada. 


\section{Palabras clave}

ius connubi, driscriminación, matrimonio, orientación sexual, derechos a la sexualidad, heteronómada, LGTB.

\section{Abstract}

The sexual orientation discrimination, marriage, homoparentality, etc., they were some of the issues under debate. We made a study on marriage equality based on international human rights texts, we raised a critical analysis (from the legal point of view) of iusconnubii, its interpretation and practical application. This analysis will also serve to assess the different formulas, along with the institution of marriage, which are presented in some countries as "alternatives" to the rights demands of LGBT; formulas that respond to very different characteristics according to the historical, sociological and policy realityof each country. Institutions considered by the human rights movements as apartheid formulas that encourage discrimination and create a limited or second categorycitizenship.

\section{Key words}

iusconnubii, discrimination, marriage, sexual orientation, sexuality rights, heteronomad, LGBT. 
Derecho y Realidad

\section{Introducción}

Las primeras jornadas de reflexión crítica que se desarrollaron en Jaén, los días 29 y 30 de marzo de 2012, bajo el título I Coloquio Internacional sobre Política y Derechos de las Sexualidades. Repensar el derecho y las políticas de las sexualidades desde el mundo latino-mediterráneo, tuvieron como objetivos, por un lado, entablar un debate sobre la manera en la que éstas se ponen en marcha en los países del sur de Europa y América Latina y, por otro, constituir una red de jurista y politólogos que trabajen en este ámbito con el fin de potenciar la investigación sobre la materia. La oportunidad de reproducir el esquema de las "categorías" (resultados del pensamiento anglosajón) a una realidad humana tan dúctil y flexible como la de las "sexualidades" y, además, hacerlo para un mundo (el latino-mediterráneo) con dinámicas y estructuras antropológicas y sociales tan diferentes, fue uno los ejes sobre los que pivotaron las reflexiones de los especialista que participaron en el evento.

En un momento en el que la revisión de la concepción heteronormada del ius connubii está siendo objeto de debate en distintas latitudes del planeta ${ }^{2}$, entendemos necesario hacer un estudio sobre la evolución de este derecho en la praxis estatal e internacional tiene un marcado carácter hermenéutico del que no escapan los legisladores nacionales y que, atendiendo a su evolución, cada vez más, se consolida el principio de no discriminación por orientación sexual en los ordenamientos jurídicos nacionales. Piénsese, por ejemplo, en el que hecho de que al día de hoy son varios los países que han introducido en sus constituciones las prohibiciones por orientación sexual: Bolivia (2009) ${ }^{3}$, Colombia (2000), Ecuador $(2008)^{4}$, Kosovo (2008), Portugal (2004), Suecia (2003), Suiza (2000) ${ }^{5}$ y Sudáfrica $(1994)^{6}$ así como

\footnotetext{
Piénsese, por ejemplo, que no son pocos los países de distintos continentes, en los que se ha abierto dicho debate y donde, incluso, se han aprobado reformas legales para permitir el matrimonio paritario. En Europa: Países Bajos, Bélgica, España, Noruega, Suecia, Portugal, Islandia y Dinamarca han otorgado reconocimiento a los matrimonios entre personas del mismo sexo. En África: Sudáfrica fue el primer país africano ( $y$ hasta el momento el único) en receptar el matrimonio igualitario mediante ley del 14 de diciembre de 2006. En (hasta el momento es el último país América Latina en aprobar una ley al respecto). Hasta aquí hemos hecho referencia a los Estados como sujetos de Derechos Internacional. Cabe señalar también que hay Estados en sistemas federales y entidades infraestatales que también lo regulan en el ámbito de sus competencias. Este es el caso de EEUU (Massachussetts, Conneticrur, Vermont, New Hampshire, lowa, distrito de Columbia - Washington D.C. - y New York), México (Distrito Federal y Quintana Roo) y Brasil (Alagoas, donde el gobierno local emitió una orden en el 2011 por la que permitía tramitar ante notario peticiones de matrimonio a las parejas del mismo sexo sin necesidad de resolución judicial).

3 Véase artículo 14 de la Constitución Política del Estado, del 7 de Febrero 2009, disponible en http:/ /bolivia.infoleyes.com/shownorm.php?id=469

4 Una nueva Constitución fue adoptada por referendo en el 2008, que protege la discriminación basada en identidad y orientación sexual. El texto de la Constitución está disponible en: http// www.asableanacional.gov.ec/documentos/Constitución-2008.pdf

5 Para más información sobre estos países, véase Itaborahy(2012, p. 18).

6 La prohibición de discriminación por orientación sexual se incluyó en la Constitución provisional, que entró en vigor el 27 de abril de 1994 (artículo 8), y más tarde agregó el artículo 9 de la Constitución de 1997 (ambos textos están disponibles en: www.info.gov.za/documents/constitution/index.htm).
} 
las de algunos territorios federados (en Argentina ${ }^{7}$, Brasil $^{8}$, Alemania $^{9}$ ) o asociados (Islas Vírgenes Británicas ${ }^{10}$ ).

Por ello, aun cuestionando la oportunidad de aplicar en nuestra cultura jurídica latino-mediterránea estructuras exógenas procedentes del mundo anglosajón, entendemos necesario, a partir de lo expuesto, realizar un análisis de en qué medida el ius connubii está siendo revisadodemocráticamente para el disfrute de toda la ciudadanía.

\section{El ius connubii y el matrimonio igualitario: estado de la cuestión}

El ius connbii se construye sobre un principio jurídico clave para el orden social que, a la vez, es reconocido universalmente como un derecho fundamental: el derecho a contraer matrimonio y fundar una familia. Derecho que, en principio, implica la posibilidad de todo individuo de contraer matrimonio de manera libre con otra personas que desee, dentro de los límites marcados por la ley; límites que, en la práctica, no se presentan, como veremos, de forma homogénea y estática, sino que manifiestan rasgos diversos y heterogéneos atendiendo a factores culturales, sociales y políticos. Así, por ejemplo, encontraremos límites de uno u otro orden (parentesco, edad, número de miembros que conforman el matrimonio, etc,) en función del momento histórico y de los rasgos de la sociedad que tomemos como ejemplo ${ }^{11}$.

Ahora bien, más allá de la praxis estatal conviene señalar que el ius connubii está amparado tanto por la protección que dispensan los textos internacionales de derechos humanos(artículo 23.2. del Pacto Internacional de Derechos Civiles y Políticos), como por aquellos que lo son de carácter regional (Convenio para la Protección de los Derecho Humanos y Libertades Fundamentales, hecho en Roma el 4 noviembre de 1950, Convención Americana sobre Derechos humanos- Pacto de San José de 1969).

A pesar de su carácter genérico, su protección y desarrollo ha estado reservado, tradicionalmente, a aquellos/as que participan de una condición sexual determinada (la heterosexual), ignorando cualquier otra fórmula que no encierre el binarismo sexual.

Artículo 11 de la Constitución de la Providencia de Buenos Arias (1996).

8 Alagoas (2001), Distrito Federal (1992), Mato Grosso (1989), Pará (2003), Santa Catarina (2002), Sergipe (1989).

9 Berlín (1995), Brandenburgo (1992), Turingia (1993). No hacemos aquí referencia a España, en cuanto no se puede definir, formalmente, como un Estado federal. Téngase en cuenta, sin embargo, que sí encontramos estas referencias en algunas Comunidades Autónomas, como la de Andalucía.

10 El artículo 26 de la Constitución de las Islas Vírgenes, Orden 2007, está disponible en: http:// www.legislation.gov.uk/uksi/2007/1678/contents/made

11 Véase un interesante estudio comparativo de la poliginia de iure y de facto existente entre USA y Sudáfrica en Bozon(2008, p. 189- 202). 
Derecho ₹ Realidad

Esta circunstancia tiene su explicación, como afirma el profesor Calvo Caravaca, en el hecho de que tanto los textos internacionales, como los nacionales que heredamos del siglo pasado (piénsese en los códigos civiles) fueron realizados en una época en la que las relaciones entre personas del mismo sexo eran objeto de sanción penal, siendo el vínculo entre el varón y la mujer la única fórmula viable. En este sentido, nos sirve como ejemplo la situación de los ordenamientos jurídicos europeos, donde la concepción de matrimonio como "unión entre varón y mujer" apareció en el Código Civil francés de 1804 (Código de Napoleón), el que, a su vez, pasaría a otros cuerpos jurídicos europeos que lo tomaron como modelo. Era tan evidente en aquella época que para que existiera "matrimonio" debía haber una relación o unión "entre hombre y mujer", que los Códigos Civiles no exigían expresamente que los contrayentes tuvieran sexo distinto, ya que se daba por entendido (Calvo-Caravaca\& Carracosa, 2005, p. 21).

Ahora bien, qué duda cabe, que las sociedades han ido evolucionado. Es evidente que poco a poco, poblaciones históricamente excluidas del disfrute del ius connubii -como ha sido el caso del colectivo LGBT-, de una forma u otra hanido disfrutando (si bien parcialmente) de derechos relacionados con la vida íntima y familiar, hasta llegar, en época recientes, al matrimonio. Proceso este, que aun siendo imparable, no es irreversible ni deja de ser controvertido, ya que, en la actualidad, el debate sobre la legalidad y el alcance del matrimonio igualitario han tomado protagonismo en la agencia política de gobierno y en la dinámica jurídica de tribunales naciones e internacionales. Sirva como ejemplo, sin ir más lejos, la reciente sentencia del Tribunal Constitucional español (2012), en la que se avala el término "matrimonio" para todos los individuos con independencia de su sexo y orientación sexual.

En este campo de batalla son numerosas las razones que esgrimen quienes se resisten a aceptar que el ius connubii puede ser disfrutado por toda la ciudadanía. Los opositores a la reforma del contrato de matrimonio se basan en argumentos de distinta naturaleza: que la unión de un hombre y de una mujer es la única definición de matrimonio (argumento semántico) (Catalano, s.f., p. 52-55); que en tanto que constituye la base la sociedad, por su capacidad de procreación no puede ser disfrutado por quienes carecen de dicha potencialidad (argumento procreativo); o que esta definición ha existido desde hace siglos, por lo que debe distinguirse del resto de pactos de protección mutua con carácter indefinido (argumento tradicional). Planteamientos, todos ellos, que han sido (y son) esgrimidos por antropólogos, movimientos religiosos e incluso juristas, pero que, a todas lucen carecen de base jurídica, ya que no aportan razones suficientes que justifiquen la pretendida discriminación. Y es que limitar el disfrute de este derecho únicamente a una parte de la sociedad (la heterosexual) supone abrir una brecha entre los derechos que todo individuo posee como nacional de un Estado (que son todos) y los que disfruta como ciudadano/a (que en ese caso se vería reducido). 
Estando así las cosas, creemos necesario, para deconstruir y desmontar todos estos argumentos, abordar la evolución del ius connubii ${ }^{12}$ a partir de los textos internacionales y la jurisprudencia desarrollada por los distintos mecanismos de derechos humanos existentes. Es conveniente, pues, ver qué es lo que realmente dicen dichos textos y cómo se interpretan para entender la verdadera dimensión de este derecho. De este modo analizaremos las resoluciones y dictámenes emanados por los mecanismos de protección del sistema universal de los derechos humanos, así como por la jurisprudencia de tribunales internacionales.

\section{La orientación sexual, aspecto del derecho a la vida privada y familiar del individuo en los sistemas de protección de derechos humanos}

De forma genérica, podríamos concluir que, de conformidad con los distintos tratados internacionales, la discriminación es toda distinción, exclusión, restricción, o preferencia basada en atributos de la persona que tiene por objeto o resultado, anular o menoscabar el reconocimiento, goce o ejercicio, en condiciones de igualdad, de derechos y libertades. En este orden de ideas, los tribunales internacionales y órganos de control entienden por discriminación por orientación sexual, identidad de género o expresión de género toda distinción, exclusión, restricción o preferencia de una persona por estos motivos con el resultado -ya sea de jure o de facto- de anular o menoscabar el reconocimiento, goce o ejercicio, en condiciones de igualdad, de sus derechos y libertades, teniendo en cuenta las atribuciones que social y culturalmente le han construido en torno a dichas categorías.

Ahora bien, dicho esto, conviene recordar que -debido a la ausencia de una regulación específica y taxativa de las categorías- la no discriminación por orientación sexual y la identidad de género se han subsumido, principalmente, en dos causales de discriminación en el ámbito del derecho internacional general, a saber: en el de discriminación por "sexo" y en la cláusula abierta, de "cualquier otra condición".

Fórmulas estas bajo las que se ha pretendido, como veremos, con mayor o menor acierto, proteger la vida familiar e íntima del colectivo LGTB.

\subsection{En el Sistema Universal de Derechos Humanos}

En el sistema universal de protección de derechos humanos encontramos varios pronunciamientos de los distintos órganos de protección que nos interesan para nuestro estudio. Este ha sido el caso, entre otros, del Comité de Derechos Humanos y el Comité de Derechos Económicos, Sociales y Culturales que calificaron la

12 Para una reflexión sobre la evolución de este derecho y de las estructuras familiares ver Pereda(2006, p. 199-208). 
orientación sexual como una de las categorías de discriminación prohibida en el artículo 2.1 del Pacto Internacional de Derechos Civiles y Políticos ${ }^{13}$ y en el artículo 2.2 del Pacto Internacional de Derechos Económicos, Sociales y Culturales ${ }^{14}$. Afirmando al respecto, el Comité de Derechos Humanos, en el caso Toonen vs. Australiaque la referencia a la categoría "sexo" incluiría la orientación sexual de las personas ${ }^{15}$. Protección que mantendría en el caso Edward Young vs. Australia ${ }^{16}$ yen el caso Xvs. Colombia ${ }^{17}$ (donde, además, se recomendaría al Estado colombiano a no discriminar por orientación sexual a la hora de estudiar el derecho a pensión, exhortándole a tomar medidas para prevenir actos de discriminación contra las parejas del mismo sexo en esta materia $)^{18}$. Línea de protección ésta que se ha visto acompañada, más allá de los simples pronunciamientos, por la preocupación que, de forma reiterada, ha manifestado el Comité de Derechos Humanos en sus observaciones finales a los informes presentados por los Estados ante las diversas situaciones discriminatorias relacionadas con la orientación sexual de las personas ${ }^{19}$.

13 Artículo 2.1 del Pacto Internacional de Derechos Civiles y Políticos: cada uno de los Estados Partes en el presente Pacto se compromete a respetar y a garantizar a todos los individuos que se encuentren en su territorio y estén sujetos a su jurisdicción los derechos reconocidos en el presente Pacto, sin distinción alguna de raza, color, sexo, idioma, religión, opinión política o de otra índole, origen nacional o social, posición económica, nacimiento o cualquier otra condición social.

14 Artículo 2.2 del Pacto Internacional de Derechos Civiles y Políticos: los Estados Partes en el presente Pacto se comprometen a garantizar el ejercicio de los derechos que en él se enuncian, sin discriminación alguna por motivos de raza, color, sexo, idioma, religión, opinión política o de otra índole, origen nacional o social, posición económica, nacimiento o cualquier otra condición social.

15 Naciones Unidas, Comité de Derechos Humanos, Toonen vs.Australia, Comunicación no. 488/ 1992, CCPR/C/50/D/488/1992, 4 de abril de 1992, párr. 8.7 ("The State party has sought the Committees guidance as to whether sexual orientation may be considered an "other status" for the purposes or article 26. The same issue could arise under article 2, paragraph 1, of the Covenant. The Committee confines itself to noting, however, that in its view, the reference to "sex" in articles 2 , paragraph 1 , and 26 is to be taken as including sexual orientation").

16 Comunicación $n^{\circ}$.941/2000, CCPR/C/78/D/941/2000, 18 de septiembre de 2003, párr. 10.4. Repetiría esta posición en las Observaciones finales, Polonia, CCPR/C/79/ Add.I 10, 25 de julio de 1999, párr. $23 .{ }^{17}$ Comunicación $n^{\circ}$. 1361/2005, CCPR/C/89/D/1361/2005, 14 de mayo 2007, párr.

18 Conviene señalar al respecto, que el Estado colombiano incumplió su compromiso internacional con el Pacto, en cuanto que, a pesar de la decisión del Comité, no tomó ninguna medida general para garantizar la igualdad en materia de pensiones entre parejas heterosexuales y del mismo sexo, dejando en manos del Congreso dicha responsabilidad. De hecho, la organización Colombia Diversa, denunció en su informe esta situación afirmando que "el 22 de agosto la directora de Seguridad Económica y Pensiones del Ministerio de Protección Social (...) y la directora de Regulación Económica de la Seguridad Social del Ministerio de Hacienda (...) emitieron un concepto desfavorable para acatar el dictamen internacional". (Colombia Diversa, 2010).

19 Cfr., inter alia,Naciones Unidas, Comité de Derechos Humanos, Observaciones finales, Chile, CCPR/ $\mathrm{C} / \mathrm{CHL} / \mathrm{CO} / 5,17$ abril 2007, párr. 16 ("Aunque observa con satisfacción la abrogación de las disposiciones que penalizaban las relaciones homosexuales entre adultos responsables, el Comité continúa preocupado ante la discriminación de la que son objeto ciertas personas debido a su orientación sexual, entre otros ámbitos, frente a los tribunales y en el acceso a la salud (artículos 2 y26 del Pacto). El Estado parte debería garantizar a todas las personas la igualdad de los derechos establecidos en el Pacto, independientemente de su orientación sexual, incluyendo igualdad ante la ley y en el acceso a los servicios de salud. Debería también poner en práctica programas de sensibilización con el fin de combatir los prejuicios sociales"); Observaciones finales, Barbados, 
Con la misma intención de proteger, pero recurriendo a otra categoría (distinta del sexo), el Comité de Derechos Económicos, Sociales y Culturales de las Naciones Unidas también indicó que

[e]n cualquier otra condición social”, tal y como se recoge en el artículo 2.2 del Pacto, se incluye la orientación sexual (...). Los Estados partes deben cerciorarse de que las preferencias sexuales de una persona no constituyan un obstáculo para hacer realidad los derechos que reconoce el Pacto, por ejemplo, a los efectos de acceder a la pensión de viudedad. La identidad de género también se reconoce como motivo prohibido de discriminación $(\ldots)^{20}$.

De forma más expresa y más directa se han pronunciado el Comité de los Derechos del Niño ${ }^{21}$, el Comité contra la Tortura ${ }^{22}$ y el Comité para la Eliminación de todas

CCPR/C/BRB/CO/3, 14 de mayo de 2007, párr. 13 ("El Comité expresa su preocupación por la discriminación que sufren los homosexuales en el Estado Parte y, en particular, por la penalización de los actos sexuales consensuales entre adultos del mismo sexo (art. 26)"); Observaciones finales, Estados Unidos de América, CCPR/C/USA/CO/3/Rev.l, 18 de diciembre de 2006, párr. 25 ("También observa con preocupación que en muchos Estados no se ha prohibido la discriminación en el empleo por motivos de orientación sexual (ara. 2y26). El Estado Parte debería aceptar su obligación jurídica en virtud de los artículos 2y26 de garantizar a todas las personas los derechos amparados por el Pacto, así como la igualdad ante la ley y la igual protección de la ley, sin discriminación por motivos de orientación sexual"); Observaciones finales, El Salvador, CCPR/CO/78/SLV, 22 de agosto de 2003, párr. 16 ("El Comité expresa su preocupación por los casos de personas atacadas, y aun muertas, con motivo de su orientación sexual (artículo 9), por el bajo número de investigaciones en relación con estos actos ilícitos, y por las disposiciones existentes (como las "Ordenanzas Contravenciones" de carácter local) utilizadas para discriminar contra las personas en razón de su orientación sexual (artículo 26)").

20 Comité de Derechos Económicos, Sociales y Culturales de las Naciones Unidas. Recomendación General $n^{\circ}$. 20: la no discriminación y los derechos económicos, sociales y culturales, E/C.12/GC/ 20. 2009, párr. 32 (véase también párrs. 15 y27). En este mismo sentido vid.Comité de Derechos Económicos, Sociales y Culturales Observación General n . 18. El derecho al trabajo, E/C.12/GC/ 18, 6de febrero de 2006, párr. 12 ("en virtud del párrafo 2del artículo 2, así como del artículo 3, el Pacto Proscribe toda discriminación en el acceso al empleo y en la conservación del mismo por motivos de [...] orientación sexual"); Observación $n^{\circ}$. 15. El derecho al agua (artículos 11 y12 del Pacto Internacional de Derechos Económicos, Sociales y Culturales), E/C 12/2002/11, 20 de enero de 2003, párr. 13 ("el Pacto proscribe toda discriminación por motivos de [...] orientación sexual"); Observación General $n^{\circ}$. 14. El derecho al disfrute del más alto nivel posible de salud (artículo 12 del Pacto Internacional de Derechos Económicos, Sociales y Culturales), E/C. 12/2000/4, 11 de agosto de 2000, párr. 18 ("En virtud de lo dispuesto en el párrafo 2 del artículo 2 y en el artículo 3 , el Pacto prohíbe toda discriminación en lo referente al acceso a la atención de la salud y los factores determinantes básicos de la salud, así como a los medios y derechos para conseguirlo, por motivos de [...] orientación sexual").

21 Cfr. Naciones Unidas, Comité de los Derechos del Niño, Observación General n . 3. EI VIH/SIDA y los derechos del niño, CRC/GC/2003/3, 17 de marzo de 2003, párr. 8("es preocupante la discriminación basada en las preferencias sexuales"); Observación General n. 4. La salud y el desarrollo de los adolescentes en el contexto de la Convención sobre los Derechos del Niño, CRC/ GC/2003/4, 21 de julio de 2003, párr. 6 ("Los Estados Partes tienen la obligación de garantizar a todos los seres humanos de menos de 18 años el disfrute de todos los derechos enunciados en la Convención, sin distinción alguna (art. 2), independientemente de "la raza, el color, el sexo, el idioma, la religión, la opinión pública o de otra índole, el origen nacional, étnico o social, la posición económica, los impedimentos físicos, el nacimiento o cualquier otra condición del niño". Deb[e] añadirse también la orientación sexual"). 
formas de Discriminación contra la Mujer ${ }^{23}$, haciendo referencias en el marco de sus observaciones generales y recomendaciones, a la orientación sexual como una de las categorías prohibidas de discriminación.

Aunque los pronunciamientos de los órganos de control de los tratados internacionales en materia de derechos humanos no han sido todo lo extensos que se hubiera deseado $^{24}$ en la protección de los derechos del colectivo homosexual, no podemos negar, sin embargo, su importancia en la aplicación del principio de no discriminación en ámbitos concernientes a la familia y a la vida privada. Circunstancias que se han visto, además, favorecidas por declaraciones y pronunciamientos de otros órganos de Naciones Unidas -como la Asamblea General de NNUU ${ }^{25}$ y el Consejo de Derechos Humanos ${ }^{26}$ - favorables a la eliminación de fórmulas que impliquen represión o discriminación. Y es que, con independencia del cumplimiento efectivo de las decisiones de los diferentes comités, éstas son la expresión de mecanismos de control creados a partir de instrumentos internacionales -obligatorios para los Estados Parte- y que, por consiguiente, gozan de una naturaleza legal vinculatoria a los efectos de modificación de legislaciones, adopción de medidas administrativas o políticas públicas que afecten a los derechos humanos ${ }^{27}$.

22 Cfr. Naciones Unidas, Comité contra la Tortura, Observación General n. 2. Aplicación del artículo 2por los Estados Partes, CAT/C/GC/2, 24 de enero de 2008, párrs. 20 y21 ("El principio de no discriminación es básico y general en la protección de los Derechos humanos y fundamental para la interpretación y aplicación de la Convención. [...] Los Estados Partes deben velar porque, en el marco de las obligaciones que han contraído en virtud de la Convención, sus leyes se apliquen en la práctica a todas las personas, cualesquiera que se[a] su [...] orientación sexual").

23 Cfr. Naciones Unidas, Comité para la Eliminación de la Discriminación de la Mujer, Recomendación General $n^{\circ} .27$ sobre las mujeres de edad y la protección de sus Derechos humanos, CEDAW/C/GC/ 27, 16 de diciembre de 2010, párr. 13 ("La discriminación que sufren las mujeres de edad con frecuencia es de carácter multidimensional, al sumarse la discriminación por [...] orientación sexual") y Proyecto de Recomendación General $n^{\circ}$. 28 relativa al artículo 2 de la Convención sobre la eliminación de todas las formas de discriminación contra la mujer, CEDAW/C/GC/28,16 de diciembre de 2010, párr. 18 ("La discriminación de la mujer por motivos de sexo y género está unida de manera indivisible a otros factores que afectan a la mujer, como la raza, el origen étnico, la religión o las creencias, la salud, el estatus, la edad, la clase, la casta, la orientación sexual").

24 Para un estudio de la protección dispensada por los órganos de control de los distintos textos internacionales en materia de Derechos humanos sobre esta materia, ver United Nations(2012).

25 El 22 de diciembre de 2008 la Asamblea General de las Naciones Unidas adoptó la "Declaración sobre Derechos humanos, orientación sexual e identidad de género", reafirmando el "principio de no discriminación, que exige que los Derechos humanos se apliquen por igual a todos los seres humanos, independientemente de su orientación sexual o identidad de género".

26 Asimismo, el 22de marzo de 2011 fue presentada, ante el Consejo de Derechos Humanos de Naciones Unidas, la "Declaración conjunta para poner alto a los actos de violencia, y a las violaciones de Derechos humanos dirigidas contra las personas por suorientación sexual e identidad de género". El 15 de junio de 2011 este mismo Consejo aprobó una resolución sobre "Derechos humanos, orientación sexual e identidad de género" en la que se expresó la "grave preocupación por los actos de violencia y diseminación, en todas las regiones del mundo, [cometidos] contra personas por su orientación sexual e identidad de género". La prohibición de discriminación por orientación sexual ha sido resaltada también en numerosos informes de los relatores especiales de Naciones Unidas.

27 Para más información sobre el papel de las resoluciones y dictámenes de órganos internacionales de derechos humanos ver Almirón (2009). 


\subsection{En el Sistema Europeo de Derechos Humanos}

En el continente europeo es, sin duda, donde mayor igualdad se ha constatado, gracias a reformas legales propiciadas en el derecho interno de los Estados y, por supuesto, al desarrollo jurisprudencial del TEDH y el Tribunal de Justicia de la Unión Europea (TJUE), cuyas sentencias han tenido (y tienen) un carácter hermenéutico para los legisladores y jueces nacionales ${ }^{28}$; llegando, incluso, a influir en decisiones de otros tribunales internacionales, como ha sido el caso de la Corte Interamericana de Derechos Humanos (CortelDH), en cuya última sentencia -Átala Riffb y niñas vs. Chile-no han faltado las continuas referencias a la jurisprudencia europea ${ }^{29}$.

En este orden de ideas, cabe señalar que el TEDH, al analizar el alcance del artículo 14 del Convenio Europeo para la protección de los Derechos Humanos enEuropa $(\mathrm{CEDH})^{30}$, ha constatado que la orientación sexual es una noción que se contempla en dicho artículo, señalando que la lista que encierra el precepto tiene un carácter indicativo y no limitativo ${ }^{31}$; insistiendo expresamente en el hecho de que, en la medida en que la orientación sexual es un concepto amparado por el art. $14 \mathrm{CEDH}$, las diferencias olas discriminaciones jurídicas basadas en la orientación sexual exigen (como viene ocurriendo con sexo) razones especialmente importantes para ser justificadas ${ }^{32}$.

28 En este sentido véanse las reflexiones hechas sobre este tema, desde la doctrina italiana, por Reale, s.f., p. 294-303=

29 Son numerosas las sentencias del TEDH citadas por la CIDH, en concreto: Caso Salgueiro da Silva Mouta vs. Portugal,(n. 33290/96), Sentencia de 21 de diciembre de 1999. Final, 21 de marzo de 2000, párr. 28. Véase también T.E.D.H., Caso Clift vs. Reino Unido,(n. 7205/07), Sentencia de 13 de julio de 2010. Final, 22 de noviembre de 2010, párr. 57; T.E.D.H., Caso Fretté vs. Francia, $\left(n^{\circ}\right.$ 36515/97), Sentencia de 26 de febrero de 2002. Final, 26 de mayo de 2002, párr. 32; T.E.D.H., Caso Kozak vs. Polonia, (n. 13102/02), Sentencia de 2de marzo de 2010. Final, 2de junio de 2010 párr. 92; Caso J.M. vs. Reino Unido,( $\mathrm{n}^{\circ}$. 37060/06), Sentencia de 28 de septiembre de 2010. Final, 28 de diciembre de 2010, párr. 55, y Caso Alekseyev vs. Russia, $\left(n^{\circ} .4916 / 07,25924 / 08\right.$ y 14599/ 09), Sentencia de 21 de octubre de 2010. Final, 11 de abril de 2011, párr. 108. Citados en Caso Karen Átala Riffb e niñas vs. Chile.Fondo, Reparaciones y Costas. Sentencia de 24 de febrero de 2012. Serie $\mathrm{Cn}^{\circ}$. 239, párr. 87.

30 Dicho artículo dispone que "El goce de los derechos y libertades reconocidos en el presente Convenio ha deberá ser asegurado sin distinción alguna, especialmente por razones de sexo, raza, color, lengua, religión, opiniones políticas u otras, origen nacional o social, pertenencia a una minoría nacional, fortuna, nacimiento o cualquier otra situación".

31 Sirva como ejemplo, entre otras, la STEDH de 21 de diciembre de 1999, caso Salgueiro DaSilva Mouta vs. Portugal, § 28. 36 SSTEDH de 9 de enero de 2003, casosL.yV vs. Austria, § 48, y S.L. vs. Austria,§ 37, ó 24 de julio de 2003, caso Karner vs. Austria, § 37, a las que se han remitido numerosas Sentencias posteriores como son las SSTEDH de 10 de febrero de 2004, caso.

32 SSTEDH de 9 de enero de 2003, casos L.yV vs. Austria,§ 48, y S.L. vs. Austria,§ 37, ó 24 de julio de 2003, caso Karnervs. Austria, § 37, a las que se han remitido numerosas Sentencias posteriores como son las SSTEDH de 10 de febrero de 2004, caso B.B. vs. Reino Unido;21 de octubre de 2004, caso Woditschkay Wilfing vs. Austria; 3 de febrero de 2005, caso Ladner vs. Austria;26 de mayo de 2005, caso Wolfineyer vs. Austriaó2 de junio de 2005, casoH.G. y G.B. vs. Austria). 
Sin ánimo de ser exhaustivo, conviene señalar algunos pronunciamientos que, sin duda, han constituido importantes avances en la construcción de la igualdad y del reconocimiento de la "vida familiar" de parejas de homosexuales y lesbianas; reconocimiento que, han contribuido a importantes conquistas. Haremos, en nuestro estudio tan solo algunas indicaciones, remitiéndonos para mayor concreción al trabajo publicado en su día por el profesor Daniel Borrillo con ocasión del aniversario de la sentencia Dudgeon vs. R. Unido (Borillo, 2011, p. 1-17).Piénsese, por ejemplo, en la posición adoptada por el TEDH en el caso Salgueiro daSilva vs. Portugalen el que determinaría que quitar la custodia aun padre por ser homosexual, constituía una violación a su derecho a la privacidad en relación con su derecho a no ser discriminado. O en la línea jurisprudencial que, en años posteriores, mantendría en una etapa calificada por el Prof. Borrillo como "de igualdad relativa (a partir de 1997)", en la que, de forma parcial, se irían reconociendo derechos vinculados a la familia y a la convivencia marital: casos Karnervs. Austria ${ }^{33}$, EB vs. Francia ${ }^{34}$, Kozac vs. Polonia ${ }^{35}$ J.M. vs. Reino Unido ${ }^{36}$, Schalk y Kopfus. Austria ${ }^{37}$, P.B. y J.S. vs. Austria ${ }^{38}$...

De toda la jurisprudencia del TEDH podemos concluir que, más allá del reconocimiento expreso del matrimonio igualitario (lo que nunca ha hecho), sí que ha "apuntalado" ciertos derechos derivados del mismo: pensiones, derechos de visitas a hijos de anteriores matrimonios, etc., que, a nuestro juicio, constituyen un paso en el camino de la igualdad.

Ahora bien, coincidimos con el profesor Borrillo cuando afirma que los avances más significativos en este ámbito, no provienen, precisamente del TEDH, sino del TJUE, el cual, en dos significativos fallos Maruko (2008) ${ }^{39}$ y Romer $(2011)^{40}$ consideró que las parejas gays en uniones civiles deben gozar de los mismos derechos de pensión que las parejas heterosexuales casadas ${ }^{41}$. Sin que por el momento, eso sí, se haya pronunciado expresamente sobre el tema del matrimonio.

33 El Tribunal determinaría que la no extensión del derecho de subrogación arrendaticia al miembro superviviente de una pareja homosexual viola el derecho a la vida privada (al domicilio) y a la no discriminación por orientación sexual STEDH, de 24 de julio de 2003.

34 Donde concluiría que la negación de la adopción por causa de la orientación sexual de la peticionaria constituía una violación a su derecho a la privacidad y a la no discriminación por orientación sexual. STEDH, de 22 de enero de 2008.

35 STEDH, de 2 de marzo de 2010.

36 STEDH, de28 de septiembre del 2010.

37 STEDH, de24 de junio de2010.

38 El caso donde se estableció que se violaba el derecho a la vida privada y a la no discriminación cuando se negaba los servicios de salud a la pareja homosexual del asegurado. STEDH, de 22 de julio de 2010. 39 STJUE de 1de abril de 2008, as. C-267/06, Maruko, Rec. 1-01757.

40 STJUE de 10 de mayo de 2011, as C- 147/08, Jürgen Rómer c. Freie und Hansestadt Hamburg.

41 De este modo, el tribunal considera que la negativa del Estado alemán a otorgar las pensiones de viudedad al Sr. Maruko y posteriormente una pensión laboral al Sr. Romer que no estaban casados, pero vivían con un contrato de unión civil "puede constituir una discriminación por razón de orientación sexual", que está prohibida por la legislación comunitaria. Borrillo, D., "De la penalización de la homosexualidad... op.rit. p. 16. 
Nos limitaremos en este apartado al análisis de la jurisprudencia del TEDH y el TJUE, sin detenernos en la protección que, a lo largo de los últimos años, se ha dispensado, desde el derecho de la UE (derecho derivado ${ }^{42}$ y originario ${ }^{43}$ ), ni en las acciones desarrolladas en el marco de la OSCE ${ }^{44}$; cuestiones que escapan del propósito de nuestro trabajo, aunque merecen ser referidas.

\subsection{En el Sistema Interamericano de Derechos Humanos}

La Comisión y la CortelDH al interpretar el artículo $1.1^{45}$ de la Convención Americana, han seguido la senda ya marcada por el TEDH que amparaba la orientación sexual dentro de la categoría de "otra condición" ${ }^{46}$, indicando al respecto que:

42 Como derecho derivado, encontramos numerosas directivas que desde el año 2000 han ido construyendo un marco favorable a la no discriminación por orientación sexual en ámbitos, sobre todo, relacionados con el trabajo. Sirvan como ejemplo, entre otras la Directiva 2005/71/CE del Consejo, de 12 de octubre de 2005, relativa aun procedimiento específico de admisión de nacionales de terceros países a efectos de investigación científica; la Directiva 2004/114/CE del Consejo, de 13 de diciembre de 2004, relativa a los requisitos de admisión de los nacionales de terceros países a efectos de estudios, intercambio de alumnos, prácticas no remuneradas o servicios de voluntariado: la Directiva 2004/83/CE del Consejo, de 29 de abril de 2004, por la que se establecen normas mínimas relativas a los requisitos para el reconocimiento y el estatuto de nacionales de terceros países o apátridas como refugiados o personas que necesitan otro tipo de protección internacional y al contenido de la protección concedida; la Directiva 2004/81/CE del Consejo, de 29 de abril de 2004, relativa a la expedición de un permiso de residencia a nacionales de terceros países que sean víctimas de la trata de seres humanos o hayan sido objeto de una acción de ayuda a la inmigración ilegal, que cooperen con las autoridades competentes; la Directiva 2003/109/CE del Consejo, de 25 de noviembre de 2003, relativa al estatuto de los nacionales de terceros países residentes de larga duración; la Directiva 2003/86/CE del Consejo, de 22 de septiembre de 2003, sobre el derecho a la reagrupación familiar, o la Directiva 2000/78/CE del Consejo, de 27 de noviembre de 2000, relativa al establecimiento de un marco general para la igualdadde trato en el empleo y la ocupación.

43 El art. 21.1 de la Carta de los derechos fundamentales de la Unión Europea, aprobada en Niza el 7 de diciembre de 2000 , contempla de manera explícita la "orientación sexual" como una de las razones en que queda prohibido ejercer cualquier tipo de discriminación.

44 La Organización para la Seguridad y la Cooperación en Europa (OSCE) ha publicado numerosos informes y documentos que exponen de manera analítica ciertos aspectos problemáticos relativos a la discriminación fundada sobre la orientación sexual o la identidad de género en el seno de los Estados participantes en la OSCE; siendo buenos ejemplos de lo expuesto los informes anuales 2006 y 2007 de la OSCE sobre los "Crímenes de odio en los países de la OSCE: incidentes y relaciones", el informe de la OSCE de 9 de marzo de 2009 sobre "Las leyes sobre los crímenes de odio: guía práctica"; el Manual sobre los derechos del hombre y libertades fundamentales del personal de las fuerzas armadas de la OSCE y el informe sobre los Defensores de Derechos Humanos en los países de la OSCE: desafíos y buenas prácticas, abril 2007-2008. Informes éstos, que en cierta medida, recogen el espíritu de la declaración de la Asamblea Parlamentaria (declaración de Ottawa) emitida en 1995 y por la que se demandaba a los Estados proveer protección igual contra la discriminación para todos. La orientación sexual fue un motivo específicamente protegido dela discriminación.

45 "[l]os Estados partes en esta Convención se comprometen a respetar los derechos y libertades reconocidos en ella y a garantizar su libre y pleno ejercicio a toda persona que esté sujeta a su jurisdicción, sin discriminación alguna por motivos de raza, color, sexo, idioma, religión, opiniones políticas o de cualquier otra índole, origen nacional o social, posición económica, nacimiento ocualquier otra condición social".

46 Por su parte, el TEDH ha establecido que la orientación sexual de una persona es un concepto que se encuentra cubierto por el Artículo 14 del Convenio Europeo de Derechos Humanos. Véase, al 
Teniendo en cuenta las obligaciones generales de respeto y garantía establecidas en el artículo 1.1 de la Convención Americana, los criterios de interpretación fijados en el artículo 29 de dicha Convención, lo estipulado en la Convención de Viena sobre el Derecho de los Tratados, las Resoluciones de la Asamblea General de la OEA, los estándares establecidos por el Tribunal Europeo y los organismos de Naciones Unidas, (...), la Corte Interamericana deja establecido que la orientación sexual y la identidad de género de las personas son categorías protegidas por la Convención ${ }^{47}$.

En este orden de ideas, y en cuanto al contenido específico del derecho a la vida privada, la Comisión sostuvo que este derecho "abarca todas las esferas de la intimidad y autonomía de un individuo, incluyendo su personalidad, su identidad, sus decisiones sobre su vida sexual, sus relaciones personales y familiares"; afirmando en relación con la orientación sexual y su vinculación con el derecho a la vida privada, que

La orientación sexual constituye un componente fundamental de la vida privada de un individuo que debe estar libre de interferencias arbitrarias y abusivas por el ejercicio del poder público (...). Existe un nexo claro entre la orientación sexual y el desarrollo de la identidad y plan de vida de un individuo, incluyendo su personalidad y sus relaciones con otros seres humanos. (...) La Comisión reitera que el derecho a la privacidad protege el derecho a determinar la propia identidad y a formar relaciones personales y familiares en base a esa identidad, aunque la misma no sea aceptada o tolerada por la mayoría ${ }^{48}$.

Estando así las cosas, es evidente que la orientación sexual, la identidad de género y la expresión de género son componentes fundamentales de la vida privada de del individuo, susceptible de protección. En este sentido, la Comisión Interamericana de Derechos Humanos (CIDH) ha enfatizado que el derecho a la vida privada garantiza esferas de la intimidad que ni el Estado ni nadie puede invadir, tales

respecto, TEDH, Caso Salgueiro da Silva Mouta vs. Portugal,(n³3290/96), Sentencia de 21 de diciembre de 1999. Final, 21 de marzo de 2000, párr. 28. Véase tambiénT.E.D.H., Caso Cliftvs. Reino Unido,(n'. 7205/07), Sentencia de 13 de julio de 2010. Final, 22 de noviembre de 2010, párr. 57; TEDH, Caso Fretté vs Francia,( $\mathrm{n}^{\circ}$. 36515/97), Sentencia de 26 de febrero de 2002. Final, 26 de mayo de 2002, párr. 32; TEDH, Caso Kozak vs. Polonia, (n. 13102/02), Sentencia de 2 de marzo de 2010. Final, 2de junio de 2010, párr. 92; Caso J.M. vs. Reino Unido, $\left(\mathrm{n}^{\circ}\right.$. 37060/06), Sentencia de 28 de septiembre de 2010. Final, 28 de diciembre de 2010, párr. 55 y Caso Alekseyev vs. Russia, $\left(n^{\circ} .4916 /\right.$ 07,25924/08 y14599/09), Sentencia de 21 de octubre de 2010. Final, 11 de abril de 2011, párr. 108 (citados en Corte IDH. Caso Karen Átala Riffby niñas vs. Chile.Fondo, Reparaciones yCostas. Sentencia de 24 de febrero de 2012. Serie $\mathrm{Cn}^{\circ}$. 239, párr. 87).

47 CortelDH. Caso Karen Átala Riffb y niñas vs. Chile. Fondo, Reparaciones y Costas. Sentencia de 24de febrero de 2012. Serie $\mathrm{Cn}^{\circ}$. 239, párr. 91.

$48 \mathrm{CIDH}$, Demanda ante la Corte IDH en el Caso de Karen Átala y niñas vs. Chile,Caso 12.502, 17deseptiembre de 2010, párrs. 111 y 116. 
como la capacidad para desarrollar la propia personalidad y determinar su propia identidad, así como campos de actividad de las personas que son propios y autónomos de cada quien, tales como sus decisiones, sus relaciones interpersonales y familiares y su hogar. De forma tal que, como se ha señalado, “el ámbito de la privacidad se caracteriza por quedar exento e inmune a las invasiones o agresiones abusivas o arbitrarias por parte de terceros o de la autoridad pública" 49 .

Pueden servirnos como laboratorio de ensayo, algunas historias reales que han ido, poco apoco, abriendo un camino de reflexión sobre este tema en tierras americanas. Piénsese, por ejemplo, en el caso de Marta Lucía Álvarez Giraldo vs. Colombia ${ }^{50}$, en el que se afirmó que negarle a la demandante el derecho a la visita íntima de su “compañera de vida" (en ese momento en prisión) podía constituir una posible violación del derecho a no ser objeto de injerencias arbitrarias o abusivas en la vida privada (art. 11 de la Convención Americana de Derechos Humanos). O en el de la señora $X$ vs. Chile, donde, a pesar de culminar en un acuerdo de solución amistosa entre las partes $^{51}$, quedó de manifiesto que la existencia de un marco regulatorio que sancionaba a policías homosexuales podía constituir una violación de la Convención.

Sin lugar a dudas, de todas las experiencias, la de mayor interés mediático y repercusión jurídica, ha sido la reciente sentencia en el caso Karen Átala vs. Chile, que ha constituido un precedente jurisprudencial en la región. Dicha sentencia no solo ha abordado la cuestión de la discriminación por orientación sexual, sino que también lo ha hecho sobre uno de los prejuicios más comunes de la sociedad latinoamericana: la creencia de que la homosexualidad afecta negativamente a los derechos del menor, población que debe ser protegida por el Estado. En efecto, la sentencia denuncia expresamente este prejuicio y constata que con él no solo se busca discriminar a lesbianas y gays, sino que se perjudica a la población que teóricamente pretende proteger ${ }^{52}$. Permite, además, que el Sistema Interamericano de Derechos Humanos dé un salto cualitativo en el continente americano en esta materia, al afirmar, como ya lo hiciera el TEDH, que lapareja homosexual constituye un núcleo familiar que debe ser objeto de protección por parte del Estado.

4954 CortelDH. Caso Karen Átala Riffb y niñas vs. Chile.Fondo, Reparaciones y Costas. Sentencia de 24 de febrero de 2012. Serie $C n^{\circ}$. 239, párr. 161, citando la jurisprudencia de dicho Tribunal en los Casos Masacres de Ituango vs. Colombia. Excepción Preliminar, Fondo, Reparaciones y Costas. Sentencia de 1de julio de 2006 SerieCn". 148, párr 194 y Caso Fontevecchiay D’Amico vs. Argentina, Fondo, Reparaciones y Costas. Sentencia de 29 de noviembre de 2011, Serie C. $n^{\circ}$. 238, párr. 48.

$50 \mathrm{CIDH}$. Informe $n^{\circ}$. 71199. Admisibilidad Petición 11.656. Marta Lucia Álvarez Giraldo vs. Colombia.4 de mayo de 1999.

51 CIDH. Informe $n^{\circ}$. 81/09. Solución amistosa. Petición 490-03. X vs. Chile, 6 de agosto de 2009.

52 En efecto, la Corte estimó que los argumentos que presuntamente justifican la diferenciación de trato por orientación sexual no cumplían con el objetivo de proteger e interés superior del niño. En ese sentido determinó que, en el caso de Karen Atalajas decisiones judiciales, al estar fundamentadas en argumentos abstractos, estereotipados o discriminatorios, constituían un trato discriminatorio en su contra violentando, los artículos 24 y1.1 de la CADH, (ver párr. 146 de la sentencia). 
Como se puede observar, partiendo de un estudio comparativo entre los sistemas de protección europeo y americano, es el Sistema Interamericano de Derechos Humanos el que menos pronunciamientos ha tenido en la materia. Sm embargo, con esta sentencia podría decirse que se consolida el marco político y jurídico en la región para el reconocimiento y protección de los derechos del colectivo LGBT. A este marco se ha contribuido no solo con la jurisprudencia de la CortelDH, sino también con las resoluciones sobre "Derechos humanos, orientación sexual e identidad de género", emitidas por la Asamblea General de la OEA con carácter anual desde el $2008^{53}$ y con la creación en el año 2011 de una unidad para los derechos de las lesbianas, los gays y las personas trans, bisexuales e intersexo por la Comisión Interamericana de Derechos Humanos ${ }^{54}$.

\section{La familia como modelo abierto de convivencia en el derecho internacional}

Como ya hemos expuesto, los instrumentos internacionales de Derechos humanos, tanto de carácter universal, como regional, consagran, por lo general, el derecho de hombres y mujeres a contraer matrimonio y conformar una familia ${ }^{55}$, de manera libre, sin discriminación ${ }^{56}$, en condiciones de igualdad para todos los miembros

53 Asamblea de la Organización de Estados Americanos. Derechos Humanos Orientación, Sexual e Identidad de Género. AG/RES. 2653 (XLI-0/11).

54 En noviembre del año 2011, la Comisión Interamericana de Derechos Humanos anunció la creación de la Unidad para los derechos de las lesbianas, los gays y las personas trans, bisexuales e intersexo, que trabaja en torno a tres pilares de trabajo: el tratamiento de casos y peticiones individuales; la asesoría a los Estados Miembros de la OEA y a los órganos políticos de la OEA; y la labor de preparación de un informe hemisférico sobre los Derechos humanos de estas personas.

55 En este sentido son varios los textos internacionales (tanto de carácter universal como regional) que reconocen este derecho. Piénsese, por ejemplo, en el artículo 23, $\mathrm{n}^{\circ} .2$ del Pacto internacional de Derechos civiles y políticos, en el que se reconoce "... el derecho del hombre y de la mujer a contraer matrimonio y a fundar una familia si tienen edad para ello", el artículo 17.2 de la Convención Americana sobre Derechos Humanos ("se reconoce el derecho del hombre y la mujer a contraer matrimonio y a fundar una familia"). Asimismo, el artículo 12 de la Convención Europea de Derechos Humanos (CEDH) también reconoce que "Los hombres y mujeres en edad de casarse tienen el derecho a contraer matrimonio y a fundar una familia, según las leyes nacionales que regulen el ejercicio de este derecho".

$56 \quad 61$ La libertad a la hora de contraer matrimonio entre las partes, también se presenta como un derecho susceptible de protección, tanto por textos internacionales como regionales. Así, el Pacto internacional de Derechos Civiles y Políticos, en su artículo $23, n^{\circ} .3$ establece que "el matrimonio no podrá celebrarse sin el libre y pleno con sentimiento de los contrayentes". En este sentido, el Pacto internacional de Derechos Económicos y Sociales, en su artículo $10 n^{\circ}$. 1afirma que "el matrimonio debe contraerse con el libre consentimiento de los cónyuges". A nivel regional, también encontramos referencias en la Convención Americana sobre Derechos Humanos, en su artículo 17 apartados 2 y 3 , en los que se dispone expresamente que "se reconoce el derecho del hombre y la mujer a contraer matrimonio y a fundar una familia si tienen la edad y las condiciones requeridas para ello por las leyes internas, en la medida en que éstas no afecten al principio de no discriminación establecido en esta Convención" y que "el matrimonio no puede celebrarse sin el libre y pleno consentimiento de los contrayentes". 
de la pareja ${ }^{57}$ y bajo la protección del Estado ${ }^{58}$. Derecho además, que como han puesto de manifiesto los tribunales internacionales, no se concibe, necesariamente, dentro de un único modelo. Circunstancia ésta que hace que "la familia" se presente como un concepto jurídico indeterminado desde el punto de vista del derecho internacional, es decir, como una "fórmula abierta" a partir de la cual los Estados podrán establecer los requisitos y las condiciones necesarias para su formación; dentro, eso sí, de los límites mínimos que impone la norma internacional y el respeto a los derechos humanos.

De hecho, de forma literal y clara, el Comité de Derechos Humanos en su Observación general $\mathrm{n}^{\circ} .19$ del año 2004, llegó a reconocer expresamente que

el concepto de familia puede diferir en algunos aspectos de un Estado a otro, y aun entre regiones dentro de un mismo Estado, de manera que no es posible dar una definición uniforme del concepto (y que..) cuando la legislación y la práctica de un Estado consideren aun grupo de personas como una familia, éste debe ser objeto de la protección prevista en el artículo 23 (del Pacto de Derechos Civiles y Políticos) $)^{59}$.

En este mismo sentido, en su Recomendación General $n^{\circ} .21$ sobre igualdad en el matrimonio y en las relaciones familiares, el Comité para la Eliminación de la Discriminación contra la Mujer también reconoció expresamente que: "la forma y el concepto de familia varían de un Estado a otro y hasta de una región a otra en un mismo Estado" 60 .

$57 \quad$ En este sentido el Pacto internacional de Derechos Civiles y Políticos, en su artículo $23, \mathrm{n}^{\circ} 4$ afirma que "los Estados partes en el presente Pacto tomarán las medidas apropiadas para asegurar la igualdad de derechos y de responsabilidades de ambos esposos en cuanto al matrimonio, durante el matrimonio y en el caso de disolución del mismo". Asimismo, la Convención Americana sobre Derechos Humanos, en su art. $17 \mathrm{n}^{\circ} .4$ establece que "los Estados partes deben tomar medidas apropiadas para asegurar la igualdad de los derechos y la adecuada equivalencia de responsabilidades de los cónyuges en cuanto al matrimonio, durante el matrimonio y en caso de disolución del mismo".

5863 Artículo 23, $n^{\circ}$. 1del Pacto internacional de Derechos civiles y políticos dispone que "la familia (...) tiene derecho a la protección de la sociedad y del Estado"; el artículo $10 \mathrm{n}^{\circ} 1$ del Pacto internacional de Derechos Económicos y Sociales afirma que "se debe conceder a la familia, que es el elemento natural y fundamental de la sociedad, la más amplia protección y asistencia posibles, especialmente para su constitución y mientras sea responsable del cuidado y la educación de los hijos a su cargo". La Convención Americana de Derechos Humanos, en su artículo 17.1 establece que "la familia es el elemento natural y fundamental de la sociedad y debe ser protegida por la sociedad y el Estado".

59 Documento HRI/GEN/I/Rev. 7, de 12 de mayo de 2004

60 Disponible en http://www.im.org/womenwatch/ckw-sp.htm. En este sentido, puede servir como ejemplo los EEUU, donde admisión del matrimonio paritario (y por tanto, la aceptación de familias donde no se reproduce el orden binario) no es una cuestión federal sino que está en manos de las legislaturas de los respectivos Estados. Así, encontramos Estados que niegan esta posibilidad, Estados que admiten la celebración de este tipo de matrimonios en su territorio y Estados que si bien no admiten la celebración de un matrimonio entre dos personas del mismo sexo dentro de su 
Fórmula abierta que, como hemos visto en páginas anteriores, también puede deducirse de los textos internacionales de carácter regional, como han puesto de manifiesto el TEDH y la CortelDH, en cuyos pronunciamientos han negado reiteradamente la existencia de un modelo único de familia ola protección exclusiva del modelo "tradicional" ${ }_{1}$. Especialmente clarificador, en este sentido, es el obiter dictumdel TEDH en el asunto Schalk y Kopfus. Austriadel 24 de junio de $2010^{62}$ en el que afirmó expresamente que

(..) el tribunal considera artificial mantener la opinión de que, a diferencia de una pareja de distinto sexo, una pareja del mismo sexo no pueda disfrutar del concepto de "vida familiar" para los propósitos del artículo 8. En consecuencia la relación de los demandantes, una cohabitación estable de una pareja del mismo sexo, que viven juntos de facto, cae dentro del concepto de "vida familiar", como una relación de una pareja de distinto sexo que estuviera enla misma situación ${ }^{63}$.

O, más recientemente, la referida sentencia de 24 de febrero de 2012 de la CortelDH en el Caso Átala Riffb y niñas vs. Chile ${ }^{64}$,en la que Chile fue condenado por "violación

territorio, le otorgan reconocimiento cuando ellos hayan sido celebrados fuera del mismo. El primer Estado en aceptar la nueva fórmula fue Massachusetts mediante ley del 17 de mayo de 2004 . Posteriormente, los Estados de Connecticut (12 de noviembre de 2008), lowa (27 de abril de 2009), Vermont (1 de septiembre de 2009) y New Hampshire (1 de enero de 2010) han admitido la celebración de este tipo de matrimonios. Así mismo, los estados de Nueva York, California, Rhode Island, New México y Washington DC reconocen validez a los matrimonios entre homosexuales celebrados en los restantes Estados o en países extranjeros aunque no regulan la posibilidad de celebrar este tipo de matrimonios dentro delos respectivos Estados.

61 Sirvan como ejemplo, entre otras sentencias, las pronunciadas por el TEDH en el Caso Salgueiro Da Silva vs. Portugalel 23 de marzo del 2000 y la sentencia de la Corte Interamericana de Derechos Humanos en el Caso Átala Riffby niñas vs. Chile, de 24 de febrero del 2012.

62 En septiembre de 2002 los austríacos Horst Michael Schalk y Johann Franz Kopf solicitaron a las autoridades municipales el permiso para contraer matrimonio. Su solicitud fue denegada por la Oficina Municipal de Viena, aludiendo que sólo las parejas de sexo opuesto pueden contraer matrimonio. Ellos interpusieron una apelación ante el Gobernador Regional de Viena, quien confirmó el punto de vista de la Oficina Municipal. En una demanda constitucional posterior, alegaron que su imposibilidad legal para contraer matrimonio, constituye una violación a su derecho al respeto de la vida privada y familiar y al principio de no discriminación. La Corte Constitucional desestimó su demanda sosteniendo que ni la Constitución austríaca ni la Convención Europea de Derechos Humanos amparaban dicho derecho. Los demandantes presentaron una solicitud para la revisión del caso a la TEDH el 5 de agosto del 2004 y ésta fue admitida. Sin embargo, ante la solicitud de que el artículo 12 de la Convención debiera interpretarse como una obligación de los Estados miembros de proporcionar el acceso al matrimonio a las parejas del mismo sexo la Corte observó que en el Consejo Europeo no hubo consenso y que dicho artículo no impone una obligación al Gobierno austríaco de conceder el acceso al matrimonio a las parejas del mismo sexo. Por lo tanto, se sostuvo por unanimidad que no hubo una violación a tal artículo. Esta sentencia está disponible en el sitio oficial de la Corte Europea de Derechos Humanos: http://www.echr.coe.int.

63 Párrafos 99-94 de la sentencia.

64 En este caso, además, En virtud a lo señalado, la CortelDH determinó que la motivación esgrimida en las resoluciones del Poder Judicial no fueron adecuadas para proteger el interés superior de las niñas y estimó que los argumentos que presuntamente justificaban la diferenciación de trato por 
al derecho a la igualdad y no discriminación" y en el que la CortelDH constató que el lenguaje utilizado por la Corte Suprema de Chile relacionado con la supuesta necesidad de las niñas de crecer en una "familia estructurada normalmente y apreciada en su medio social" y no en una "familia excepcional", reflejaba una percepción limitada y estereotipada del concepto de familia que no tiene base en la Convención al no existir un modelo específico de ella (la "familia tradicional").

En otro orden de ideas, y por lo que al carácter reproductivo del matrimonio se refiere, (argumento utilizado, como vimos, por los que se oponen al matrimonio igualitario) parece evidente, asimismo, que existe una disociación entre la institución del matrimonio y los derechos reproductivos y sexuales. De hecho, a partir de la Conferencia Internacional sobre la Población y el Desarrollo, llevada a cabo en El Cairo en 1994, existe un consenso internacional en tono al concepto de "derechos sexuales y reproductivos" como derechos cuyo ejercicio derivan directamente de los Derechos humanos, sin que en ningún caso se hayan circunscrito a un fin o en un marco determinado. Como su nombre indica, éstos se refieren al conjunto de derechos que es necesario satisfacer con el fin de que todos los aspeaos ligados a la sexualidad y la reproducción humana puedan expresarse en condiciones de libertad y dignidad. En este sentido, el Programa de Acción de la Conferencia Internacional sobre la Población y el Desarrollose refiere no solo al derecho de todo individuo, sin ninguna discriminación, a tomar decisiones libres sobre su reproducción, sino también al compromiso de los Estados de propiciar las condiciones necesarias para que esas decisiones se puedan ejecutar. En este marco, el principio $\mathrm{n}^{\circ} .8 \mathrm{del}$ citado programa de acción establece que

"todas las parejas y todas las personas tienen el derecho fundamental de decidir libre y responsablemente el número y el espaciamiento de sus hijos y de disponer de la información, la educación y los medios necesarios para ello y el derecho alcanzar el nivel más elevado de salud sexual y reproductiva" ${ }^{65}$.

Ahora bien, visto todo esto, puede concluirse que el ius connubiies un derecho del que, a priori, pueden disfrutar todos los individuos con independencia de su orientación sexual y que el matrimonio, como fórmula jurídica de convivencia, no detenta el monopolio del desarrollo de la vida familiar e íntima, pudiendo existir ésta más allá de sus fronteras jurídicas. Planteándose éste, además, como un marco prescindiblepara la reproducción.

orientación sexual no cumplían con el objetivo de proteger el interés superior del niño. En ese sentido determinó que, en el caso de Karen Átala, las decisiones judiciales, al estar fundamentadas en argumentos abstractos, estereotipados y/o discriminatorios, constituían un trato discriminatorio en su contra violentando, los artículos 24 y1.1 de la CADH. (Ver párrafo 146 de la sentencia).

65 Disponible en http.7/www.unfpa.org/icpd/icpd-programme_spa.cfm. 


\section{El ius connubii como derecho fundamental de geometría variable en el tiempo y en el espacio}

Como ya hemos apuntado, tanto en el Sistema de Protección Universal de Derechos Humanos ${ }^{66}$, como en el regional ${ }^{67}$, se reconoce de forma expresa el derecho del hombre y la mujer de contraer matrimonio y fundar una familia. Ahora bien, teniendo en cuenta el contenido de los textos en los que se reconoce este derecho, puede concluirse que, a priori, no existe nada que impida su ejercicio por una pareja formada por individuos del mismo sexo, ya que los únicos límites que establecen los textos internacionales de forma expresa para su disfrute son el de la edad y "las condiciones establecidas por cada Estado", lo que implica, a la postre, fundamentar su ejercicio en un acto volitivo de éste último. Precisamente estas fórmulas abiertas del ius connubiiy de la "familia", así como el amplio margen de los Estados a la hora de regular las instituciones y los derechos, explican que tanto la aceptación del matrimonio igualitario, como la negación del mismo no constituyen per seviolaciones de los citados textos internacionales; afirmación que, por otra parte, han puesto de manifiesto, el Comité de Derechos Humanos en 1999 (en el caso de Juliet Joslin y otras vs. el Estado de Nueva Zelanda ${ }^{68}$ o el TEDH (en el caso Schalk y Kopfvs. Austria) ${ }^{69}$.

Y es que, a nuestro juicio, lo realmente interesante es aquello que "no" dice el Comité ni el TEDH en sus pronunciamientos: ni uno ni otro niegan que dos personas del mismo sexo puedan contraer matrimonio, sino que, haciendo una interpretación literal de la norma internacional, y sobre la base del amplio margen de maniobra que tiene el Estado a la hora de regular este derecho, sostienen que la limitación del ius connubii no constituye una violación de la norma internacional, como tampoco lo constituiría a sensu contrario una interpretación amplia del mismo.

66 La Declaración Universal de Derechos Humanos señala que "Los hombres y las mujeres, a partir de la edad núbil, tienen derecho, sin restricción alguna por motivos de raza, nacionalidad o religión, a casarse y fundar una familia". Dicho derecho, también viene reconocido y regulado por el Pacto Internacional de Derechos Civiles y Políticos, en el artículo 23.2, en el que se "reconoce el derecho del hombre y de la mujer a contraer matrimonio y a fundar una familia si tienen edad para ello".

67 En este mismo sentido, encontramos reconocido dicho derecho en textos internacionales de carácter regional, entre los que destacan el artículo 17.2 de la Convención Americana sobre Derechos Humanos, en el que "Se reconoce el derecho del hombre y la mujer a contraer matrimonio y a fundar una familia si tienen la edad y las condiciones requeridas para ello por las leyes internas, en la medida en que éstas no afecten al principio de no discriminación establecido en esta Convención" o el artículo 12 de la Convención Europea de Derechos Humanos, en el que se dispone "A partir de la edad núbil, el hombre y la mujer tienen derecho a casarse y a fundar una familia según las leyes nacionales que rijan el ejercicio de este derecho".

68 En este caso el Comité afirmó que "En vista del alcance del derecho al matrimonio conforme al párrafo 2del artículo 23 del Pacto, el Comité no puede considerar que por el mero hecho de negar el matrimonio entre personas homosexuales el Estado Parte haya violado los derechos (consagrados en el Pacto)".

69 En su fallo del 2010, en el caso Schalk yKopfvs. Austria(demanda $n^{\circ}$. 30141/04), en la que determinó que la CEDH no obliga a los Estados miembros a legalizar o reconocer legalmente los matrimonios entre personas del mismo sexo, no constituyendo la ausencia de legislación en este sentido una violación del artículo 12 de la CEDH. 
Quizá todo esto explique, algo que también es evidente, la adaptabilidad del matrimonio en el espacio y la relatividad de sus elementos en el tiempo. Por lo que a la relatividad del concepto en el espacio se refiere, es evidente que el matrimonio es una institución cuyo concepto y contenido jurídico ha variado (y varía) enormemente según el círculo cultural en el que nos movamos. Así, por ejemplo, el "matrimonio" que regula el derecho musulmán (en el que queda permitida la poligamia) es algo bien diferente del recogido en los códigos civiles occidentales, donde, por otra parte, tampoco se manifiesta homogeneidad en su estructura. Piénsese, por ejemplo, el hecho de que dentro del mismo marco de pensamiento jurídico (el occidental) hay ordenamientos jurídicos que, al día de hoy, solo admiten el matrimonio heterosexual, mientras que otros, desde hace años, aceptan el matrimonio igualitario ${ }^{70}$, existiendo, incluso, dentro de estos últimos asimetrías en sus efectos jurídicos ${ }^{71}$.

Por lo que respecta a su relatividad en el tiempo, coincidimos con el profesor Calvo Caravaca, cuando afirma que su concepto jurídico no siempre ha sido el mismo a lo largo de la historia, llegando a evolucionar incluso en los ordenamientos jurídicos occidentales. De hecho, como señala este autor, el concepto de matrimonio que hoy se acepta en la inmensa mayoría del mundo occidental no coincide con el concepto jurídico de matrimonio de la tradición jurídica anglosajona ${ }^{72}$ o canónica romana $^{73}$, en la que se concebía como "unión voluntaria para toda la vida" y de la que derivan la creencia de que el binarismo sexual debe pervivir en dicha institución.

Tampoco han faltado tribunales nacionales de rango constitucional que parecen alinearse en esta posición. Uno de los ejemplos más llamativos ha sido, entre otros, el de la Corte Constitucional Sudafricana que afirmó en el 2005 que

$70 \quad$ Países Bajos (desde el 2001), Bélgica (desde el 2003), España (desde el 2005), Canadá (desde el 2005), Sudáfrica (desde el 2006), Noruega (desde el 2009), Suecia (desde el 2009), Suecia (desde el 2009), Portugal (desde el 2010), Islandia (desde el 2010) y Argentina (desde el 2010), Dinamarca (desde el 2012), Francia (desde el 2012), y en algunas partes de México (Distrito Federal) y Estados Unidos (Connecticut, Distrito de Columbia, lowa, Massachusetts, New Hampshire, New York y Vermont).

71 Hay Estados, como Portugal, en los que se reconoce el matrimonio igualitario, pero sin derecho a adopción; mientras que hay otros, como por ejemplo España, donde el matrimonio entre personas del mismo sexo, tiene exactamente los mismos derechos que entre personas del mismo sexo.

72 Sirva como starting pointel típico y tradicional concepto inglés sobre lo que es, o era, el matrimonio. En Hyde vs. Hyde(1866) se contiene la clásica definición de "matrimonio" proporcionada por la jurisprudencia inglesa y debida a Lord Pendanze: el matrimonio es "the voluntary unión for life of one man anda one woman to the exclusión o fall others" (1886) LR 1P\&D130; Clarkson, CH.M.V.I Hill, J./Jaffey, A.J.E, Jaffey on the Confia of Laws, 2a ed., London, Butterworths, 2002, p. 354. En Calvo Caravaca, A.L./Carrascosa González, J., "Derecho internacional privado y matrimonios... op. cit.,p. 16 .

73 Modestino: "Nuptiae sunt coniunctio maris et feminae et consortium omnis vitae, divini et humani juris communicatio" (Modestino, Digesto, 23.2.1). En Calvo Caravaca, A.L./Carrascosa González, J., "Derecho internacional privado y matrimonios... op. cit.,p. 16. 
A pesar de que es cierto que el derecho internacional protege expresamente el matrimonio heterosexual, no es cierto que lo hace excluyendo necesariamente el reconocimiento que ya se hace y que irá haciendo en el futuro del derecho de las parejas del mismo sexo a disfrutar del estatuto, derechos y responsabilidades otorgados al matrimonio de las parejas heterosexuales ${ }^{74}$.

O la Corte Constitucional de Colombia, en cuya sentencia C-577 de 2011 ratificó que las parejas del mismo sexo conforman un tipo de familia reconocida por la Constitución colombiana de 1991, exhortando al Congreso de la República a emitir una ley que elimine la falta de protección de parejas del mismo sexo antes del 20 de junio de $2013^{75}$. O, sin ir más lejos, la reciente sentencia del Tribunal Constitucional español en la que, tras un largo periodo de deliberación se ha avalado por una amplia mayoría de sus miembros la reforma introducida por el gobierno en el año 2005, por la que se abre el matrimonio apersonas del mismo sexo.

\section{Conclusión}

La protección del individuo y su no discriminación por orientación sexual, viene garantizada mediante su inclusión en las categorías "sexo" u "otra condición..." que figuran en las cláusulas de no discriminación de textos internacionales de carácter universal y regional. Textos, que además, conceptualizan el ius connubii, como un derecho fundamental abierto, amplio y con pocas limitaciones a priori. Circunstancia ésta que viene respaldada por las decisiones emanadas de los mecanismos de control de tratados internacionales de Derechos humanos y por la jurisprudencia de tribunales internacionales (entre los que destacan, por su importancia y autoridad en la materia, el TEDH y la Corte IDH). Decisiones y jurisprudencia que parecen haber desdibujado los contornos (hasta ahora) sólidos de realidades sociales (la familia) e instituciones jurídicas (el matrimonio) concebidos, tradicionalmente, desde una óptica heteronormada.

Ahora bien, a pesar de que es innegable el avance en materia de derechos de lesbianas y gays en ámbitos concernientes a la vida privada y familiar; no puede ignorarse que aún queda mucho por hacer en el reconocimiento pleno de derechos en materia de matrimonio y filiación. Precisamente, por la amplitud conceptual del ius connubii, que deja en manos de los Estados la regulación de su disfrute y

\footnotetext{
Caso CCT 60/04 de 2005, MinisterofHomeAffair vs. Fourie, Corte Constitucional Sudafricana.

75 En dicha sentencia, además, la Corte señala (apartado 2.10.1.4) que es cierto que la protección a las familias fundadas en un matrimonio entre personas de sexo distinto "es un dato constitucional insoslayable con el que tiene que contar el juez constitucional al momento de resolver asuntos como los planteados en las demandas que ahora se deciden y [...]", pero ello no justifica invertir el juicio de constitucionalidad como lo propone la sentencia, ni restringir el matrimonio a una institución exclusivamente para parejas de personas del mismo sexo.
} 
desarrollo normativo, es por lo que en la práctica asistimos a un relativismo en el espacio y en el tiempo del contrato de matrimonio, circunstancias, todas ellas, que hacen que dicho derecho se presente en la práctica (parafraseando al profesor $\mathrm{H}$. Muir Watt) como un derecho fundamental abierto de geometría variable (1997, $\mathrm{p}$. 403-415). Hecho éste que, puede tener tanto una lectura positiva (la posibilidad de modificar estructuras jurídicas que limitan su ejercicio a toda la ciudadanía) como negativa: la proliferación de instituciones apartheid (uniones civiles, las parejas de hecho, etc. ${ }^{76}$ ) que en el fondo no hacen sino reforzar los esquemas de una sociedad patriarcal y que buscan alternativas jurídicas, antes de replantear el orden binario del contrato de matrimonio. Situación está que, como ha quedado demostrado, fomenta una discriminación injustificada y crea ciudadanos/as de segunda clase: homosexuales o lesbianas, tienen todos los derechos y obligaciones como nacionales, pero solo parte de los derechos como ciudadanos.

\section{Lista de Referencias}

Almirón, E.(2009). Aplicación de las resoluciones emanadas de órganos internacionales de derechos humanos y su eficacia en el derecho interno. Asunción: Corte Suprema de Paraguay.

Borrillo, D. (2005). Who is breaking with tradition? The legal recognition of samesex partnership in France and question of modernity? Yale Journal of Law Feminism, 17, 89-97.

Borrillo, D. (2010). El pacto civil de solidaridad ¿Contractualización del matrimonio o matrimonialización de la convivencia more uxorio? Revista Interdisciplinar de Doctrina y Jurisprudencia, Derecho de Familia,(46). Buenos Aires, Bogotá, México, Santiago: Abeledo Perot.

Borrillo, D. (2011). De la penalización de la homosexualidad a la criminalización de la homofobia: el Tribunal Europeo de Derechos Humanos y la orientación sexual. Revista de Estudios Jurídicos, (11) (Segunda época), 1-17. Recuperado de rej.ujaen.es

Bozon, M. (2008). États-Unis/Afrique du Sud. La polygyny au miroir du marriage homoseuxal. In V. Descoutures. Mariages et homosexualités dans le monde Autrement, Mutation (pp. 189-202). S.1.: s.n.

Calvo-Caravaca, A.L. \&Carracosa, J. (2005). Derecho internacional privado y matrimonios entre personas del mismo sexo.Anales de Derecho. Universidad de Murcia, (23), 21.

76 Una de estas fórmulas alternativas al matrimonio ha sido, por ejemplo, el PaCS en Francia. Para un estudio del mismo y sus efectos, verBorrillo (2010, p. 39-47; 2005, p. 89-97). 
Catalano, R. Note sul percorso evolutivo concernente la nozione di grupo familiar. En Bin, R. Brunelli, G. Guazzarotti\& A. Veronesi, PS, (a cura di). La "Societá natural" e i suoi "nemici", Sul paradigm eterosessuale del matrimonio. (pp.52-55). Torino: Giappichelli.

Colombia Diversa (2010, mayo). Situación de derechos humanos de la población LGBT, Informe Alterno presentado al Comité de Derechos Humanos de Naciones Unidas. S.1.: s.n.

Itaborahy, L.P.(2012). Homofobia de Estado. Un informe mundial sobre las leyes que criminalizan la actividad sexual con consentimiento entre personas adultas del mismo sexo. ILGA. Recuperado de ilga.org

Muir-Watt, H. (1997). Les príncipes généraux en droit international privé francais. JDI Clunet, 403-415.

Pereda, J. (2006). El cambio de las estructuras familiares y la modernización del derecho de familia (nota para tertulia). En S. Navas (Dir.). Matrimonio homosexual y adopción. Perspectiva nacional e internacional. (pp. 199-208). Madrid: Días-Bastien \& Truan.

Pezzini, B. (2010). Dentro il mestiere di vivere: uguali in natura o uguali in diritto?. En Bin, Brunelli, R., Guazzarotti, G. \&Veronesi, A. PS, (a cura di). La "Societá natural" e i suoi "nemici", Sul paradigm eterosessuale del matrimonio. (pp. 1-25). Torino: Giappichelli.

Reale, A. Giudice ordinario einterpretazione delle norme giuridiche. En Bin, Brunelli, R., Guazzarotti, G. \&Veronesi, A. PS, (a cura di).La "Societá natural" e i suoi "nemici", Sul paradigm eterosessuale del matrimonio. (pp. 294-303). Torino: Giappichelli.

Tribunal Constitucional español. (2012, 28 de nov.). STC 198/2012. BOE.

United Nations Organization.(2012). Human Rights Office of the High Commissioner. Bornfree and equal. Sexual Orientation and Gender Identity in International Human. New York and Geneve: UNO. 